\title{
Efficacy of Intense Pulse Light with Triple Combination Cream Versus Triple Combination Cream alone in the Treatment of Melasma
}

\author{
Anshul Verma', Sudha Agrawal ${ }^{2}$
}

${ }^{1}$ Srishti Hospital \& Research Centre, Dibrugarh, Assam, India; ${ }^{2}$ B.P. Koirala Institute of Health Sciences, Dharan, Nepal

\begin{abstract}
Introduction: Various studies explored the use of intense pulse light (IPL) therapy in treating melasma, but only a few randomized clinical trials have evaluated the combination of triple combination cream (TCC) with IPL so far.

Objective: This study compared the efficacy and safety of the combination of IPL and triple combination cream with triple combination cream alone in treating melasma.

Material and Methods: Sixty patients with melasma were enrolled in this assessor-blinded, parallel-group randomized controlled study. Thirty patients were treated with IPL (15J/ $\mathrm{cm}^{2}$, two sessions at 2-week intervals) and TCC (Hydroquinone $2 \%$, tretinoin $0.025 \%$, fluocinolone acetonide $0.01 \%$ ) at night and broad-spectrum sunscreen during day time whereas other groups received only TCC and broad-spectrum sunscreen. The median percentage reduction in melasma area and severity index (MASI) and physician's global assessment scale was assessed at 12-week to determine the efficacy of the treatment. The incidence of adverse effects at each follow-up and relapse at 16-week were also noted during the study period as the secondary outcome measure.
\end{abstract}

Results: The median reduction in MASI achieved at 12 weeks was $48 \%$ in the IPL+TCC group and $13.1 \%$ in the TCC group from the baseline. The incidence of relapse was seen in $7.14 \%$ and $13.04 \%$ patients in the IPL+TCC group and TCC alone group respectively at 16 weeks however, this difference was not statistically significant $(p<0.05)$.

Conclusion: Our study supports that IPL and TCC are more effective than TCC therapy alone in treating melasma.

Key words: Drug therapy; Hyperpigmentation; Light therapy; Melanosis; Melasma treatment, Pigmentary disorders

\section{Introduction}

$\mathrm{M}$ elasma is an acquired disorder of symmetrical hyperpigmentation, appearing as light to dark brown macules and patches on the face, especially the forehead, malar areas, and chin. The exact prevalence of melasma is unknown, but it is probably more prevalent in people with darker skin Fitzpatrick skin phototypes III to V. The management of melasma is often challenging, with incomplete responses and frequent relapses. No single treatment has been proven to be the most effective. ${ }^{1,2}$ Therefore, combination treatment using several possible modalities has been preferred, and topical bleaching or whitening

Funding: No

Conflict of Interest: No

\section{Address of Correspondence}

Dr. Anshul Verma, MD

ORCID ID: 0000-0002-5654-0351

Flat 1D, Luit View apartments, Circuit house road, Dibrugarh, Assam, India

Mobile no.:0091-9717120001

E-mail: verma.anshul17@gmail.com agents along with chemical peels and or light-based treatments have been generally adopted. . $^{3,4}$ The topical therapies are the first-line therapy in the management of melasma. Of which, triple combination therapy (TCC) is more efficacious and faster acting than dual therapy or monotherapy with hydroquinone, tretinoin, or the topical corticosteroid. However, pharmacologically active molecules can result in important side effects such as ochronosis induced by hydroquinone and/or irritation and skin atrophy induced by tretinoin and corticosteroids. $^{3,4}$

Date of Submission: $1^{\text {st }}$ July 2021

Date of Acceptance: $20^{\text {th }}$ August 2021

Date of Publication: $1^{\text {st }}$ October 2021

How to cite this article

Verma A, Agrawal S. Efficacy of Intense Pulse Light with Triple Combination Cream Versus Triple Combination Cream alone in the Treatment of Melasma. NJDVL 2021;19(2):13-21. https:// doi.org/10.3126/njdvl.v19i2.38557.

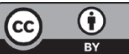

Licensed under CC BY 4.0 International License which permits use, distribution and reproduction in any medium, provided the original work is properly cited. 
In recent years, laser and light-based therapies have emerged as an alternative for the treatment, especially in refractory cases. Intense pulsed light (IPL) is a non-laser light source that emits light with a broad-spectrum wavelength between 515 and 1200 $\mathrm{nm}$. It provides a level of selective photothermolysis, which targets all skin chromophores (melanin, haemoglobin, water) and thus, it can treat pigment and vascular components involved in the pathogenesis of melasma. ${ }^{5}$ It has an advantage over Q-switched lasers therapies by targeting both epidermal and dermal melasma simultaneously (the use of a spectrum of wavelengths), providing greater thermal diffusion, reduces the chance of thermal related postinflammatory pigmentation (range millisecond pulse duration) and covering rapid large areas of melasma (large IPL head than most laser spot sizes of laser). However, it is associated with fewer side effects such as post-inflammatory hyperpigmentation. ${ }^{6}$

Numerous studies have explored the possibility of combined therapy involving intense pulsed light to date. However only a few randomized studies have assessed the efficacy so far, and a recently published meta-analysis-based assessment of IPL suggested that IPL may be effective in the treatment of melasma. ${ }^{7-11}$ However, the authors concluded that there were methodological flaws in the included studies. ${ }^{11}$ In a clinical trial from Pakistan, intense pulse light therapy and triple combination cream were more efficacious than intense pulse light therapy and triple combination cream alone in the treatment of melasma. ${ }^{10}$ The use of a combination of TCC may also reduce the treatment failure. ${ }^{9}$ The present study evaluated the efficacy and safety of light therapy in combination with triple combination cream vs. triple combination cream alone in the treatment of melasma. The incidence of relapse of melasma was assessed after 4 weeks of stopping the treatment in both groups.

\section{Materials and Methods}

\section{Patients}

This was an assessor-blinded, randomized controlled study of 60 patients with melasma, who were randomly allocated to receive IPL+TCC or TCC alone therapy based on a randomization list (1:1 patient) generated with the help of computer-generated random numbers. The sequentially numbered list with the treatment group written on a sealed brown envelope was provided by an independent dermatologist. The exclusion criteria for the study were less than 18 years age, pregnancy and lactation, history of usage of photosensitive drugs, patients currently on contraceptives and hormone replacement therapy, known hypersensitivity to study products, history of recurrent herpes simplex infection, keloidal tendency, endocrine and metabolic illness. For patients using topical steroids, topical bleaching agents, chemical peeling, laser therapy or IPL, a washout period of at least one month was considered. Informed and written consent were obtained from each patient before enrolment. Detailed history and clinical examination were performed and recorded in a pre-set proforma. The ethical clearance was obtained from the Institutional Review Committee.

\section{Determination of sample size}

We estimated sample size with the difference of a mean of 4 with a Standard deviation (SD) of 5.2 on the Melasma Area and Severity Index. A sample size of 54 patients was needed to have a power of $80 \%$ with an alpha error of $5 \%$, and hence to allow for potential participant loss, we recruited 30 patients in each group.

\section{Study treatment groups \\ Group A:}

The patients were given a topical triple combination cream (Hydroquinone 2\%, tretinoin 0.025\%, fluocinolone acetonide $0.01 \%$ ), which they applied once daily, after washing the affected area at night, at least 30 minutes before bedtime for 4 weeks. Then it was tapered to five days per week for 4 weeks and finally two nights per week for another 4 weeks. If skin irritation symptoms developed, such as erythema, a burning sensation, or desquamation, treatment frequency was reduced, and daily application was resumed when symptoms subsided. The total duration of topical cream was instructed to use for 12 weeks.

\section{Group B:}

In addition to topical triple combination cream (Hydroquinone $2 \%$, tretinoin $0.025 \%$, fluocinolone acetonide $0.01 \%$ ) as in group $A$, the patients were treated with 2 sittings of IPL (emitting 560 1200 nm). The treatment parameters used were a 590-nm cut-off filter, fluence $15 \mathrm{~J} / \mathrm{cm}^{2}$, pulse width $3 \mathrm{~ms}$, a delay time of $30 \mathrm{~ms}$ between pulses, and double pulses, along with an inbuilt skin cooling system. Ultrasound gel was used to protect the epidermis and support the light to deliver uniformly onto the skin surface. No topical anesthesia was used before the procedure. The clinical endpoint of IPL treatment was mild erythema vanishing in less than 30 minutes with ice pack application. After two weeks, the patient was asked to follow up, and the same setting of IPL was repeated.

All patients were instructed to avoid sun exposure and to apply a broad-spectrum sunscreen with a sunprotection factor of $50+$ for 16 weeks. 


\section{Assessment of therapy and follow-up}

The percentage of decrease in the appearance of melasma by clinical and photographic evaluations \& any adverse effects present were assessed by a blinded dermatologist at each follow-up visit (weeks 0, 4, 8, 12 and 16). The melasma Area and Severity Index (MASI) and Physician's Global assessment scale were used for assessment of the changes in pigmentation after treatment. The melasma Severity Scale was assessed as Forehead 0.3(D+H) A + Rt. Malar 0.3(D+H) A + Lt. Malar 0.3 $(D+H) A+$ Chin 0.1 $(D+H) A$. The total index ranges from 0 to 48 , with the higher score indicating more severe disease. ${ }^{12}$

The Physician's Global Assessment is a subjective measure of change in the severity of pigmentation from baseline. A 7-point scoring system ${ }^{9}$ was used: 0 = clear (91-100\%) except for possible residual discoloration; 1=almost clear (76-90\%) only minor evidence of hyperpigmentation remains; $2=$ marked improvement (51-75\%) some disease evidence of hyperpigmentation remains; $3=$ moderate improvement (26-50\%) intermediate between slight and marked improvement; 4=slight improvement (25\%) significant evidence of hyperpigmentation remains; 5=no improvement; hyperpigmented condition unchanged; $6=$ worse; condition worse than at 0 week. Standard digital photographs were taken by a digital camera (10.0 MP; Samsung) under the same circumstances (from the front view, oblique and side views under the same lighting conditions) at each visit.

\section{Adherence}

The amount of study drug used per patient, i.e., the amount of tube used, was assessed at each visit.

\section{Evaluation of treatment efficacy}

Treatment efficacy was measured after the completion of therapy at week 12 by the percentage reduction in MASI and improvement of hyperpigmented lesions by Physician's Global Assessment. It was graded as clear, almost clear, marked improvement, moderate improvement, slight improvement, no improvement and worse. ${ }^{9}$ In addition, the patients were asked for their subjective satisfaction with the treatment as good, fair, poor or very poor.

\section{Relapse}

The incidence of relapse was assessed after 4 weeks of completion of the treatment. It was defined by $>25 \%$ increment in the pigmentation (MASI) after completion of treatment at week 16.

\section{Assessment of Adverse events (AEs)}

Patients were assessed for any adverse events (AEs), including any possible complications and side effects (erythema, edema, burning, petechiae, acute urticaria, telangiectasia, post-inflammatory hypopigmentation and hyperpigmentation) either those sufficiently serious enough to stop the intervention or minor adverse events not requiring withdrawal and were recorded at each treatment session and during follow up visits.

\section{Data management and statistical analysis}

After completing of the study, the data was compiled, and double-checked in Microsoft Excel, and then analysis was done by using the software program Statistical Package for the Social Sciences software (version 10.0; SPSS Inc., Chicago, IL, USA). Comparison between the groups regarding categorical variables was tested using Chi-square test or Fisher's exact test whereas paired and unpaired Student's t-test or Wilcoxon rank-sum test and Mann Whitney $U$ test for parametric and non-parametric tests respectively. Statistical significance was considered at $p<0.05$.

\section{Results}

\section{Patient characteristics}

Of the total 60 patients enrolled, 51 patients completed the study. Figure 1 shows the flow diagram of participants in the study.

The demographic characteristics are given in Table 1. There was no statistical difference between the two groups.

\section{Treatment Outcome analysis}

Table 2 depicts the MASI score at baseline and at follow - up in both the groups.

The median percentage of improvement in both IPL+TCC and TCC alone groups is shown in Figure 2. The median percentage reduction in MASI at the end of 12 weeks was $48 \%$ in IPL+TCC group and $13.08 \%$ in TCC alone group. The median percentage reduction favored of the IPL+TCC group, which was statistically significant $(p<0.05)$. In the $16^{\text {th }}$ week the median MASI score was 9.8, reduced by $34.6 \%$ from baseline in IPL+TCC whereas, the score was 14.35 , with a $16.5 \%$ reduction in TCC alone group. Before and after photos of 2 patients with improvement in MASI scores after IPL + TCC treatment and TCC alone are shown in Figure 3 and Figure 4.

\section{Physician's global assessment}

Physician's global assessment observed almost clear to moderate response in 7 patients $(25.0 \%)$ at 4 weeks follow up in IPL + TCC group. The number of clearance 
was further increased in 13 patients (46.4\%), and 16 patients (57.2\%) at subsequent follow up at 8 weeks and 12 weeks, respectively, but the response was decreased at 16 weeks (42.8\%). In the TCC alone group, almost clear to moderate response was more seen in 7 patients (30.4\%) at 4 weeks follow up, but it was decreased during subsequent follow up at 8 weeks (26.1\%), 12 weeks (21.7\%) and 16 weeks (21.7\%) respectively (Table 3 ).

\section{Relapse}

After four months, the relapse was observed in 2 (7.14\%) patients in IPL + TCC group and 3 patients (13.04 \%) in TCC group (Table 4).

\section{Patient's satisfaction}

In IPL+TCC group, 11 (39.3\%) patients had good satisfaction score at 4 weeks. At 8 weeks, 18 (64.3\%) patients had good satisfaction scores. At 12 weeks, 22 (78.5\%) of patients had good satisfaction scores. At 16 weeks, the percentage reduced to $17(60.7 \%)$ patients with good satisfaction scores. In the TCC group, 11 (47.8\%) patients had good satisfaction scores at 4 weeks and 11 (47.8\%) at 8 weeks. At 12 weeks and 16 weeks, the percentage of good satisfaction decreased to 9 (39.1\%). Patient's satisfaction between IPL+TCC group and TCC group was significant at 12 weeks ( $p=$ 0.032), with a better satisfaction score in the IPL+TCC group. However, there was no statistical difference $(p=0.308)$ between the groups at 16 weeks.

\section{Adverse effects}

On every follow-up, local skin tolerability variables (erythema, burning) and various other side effects were noted. In IPL+TCC group, 28 (100\%) patients had at least one local sign/symptom developed during the entire follow-up period. Likewise, 23 (100\%) patients in the TCC group experienced at least one local sign/ symptom during the follow-ups (Table 5). None of the patients in both groups experienced any serious adverse effects.

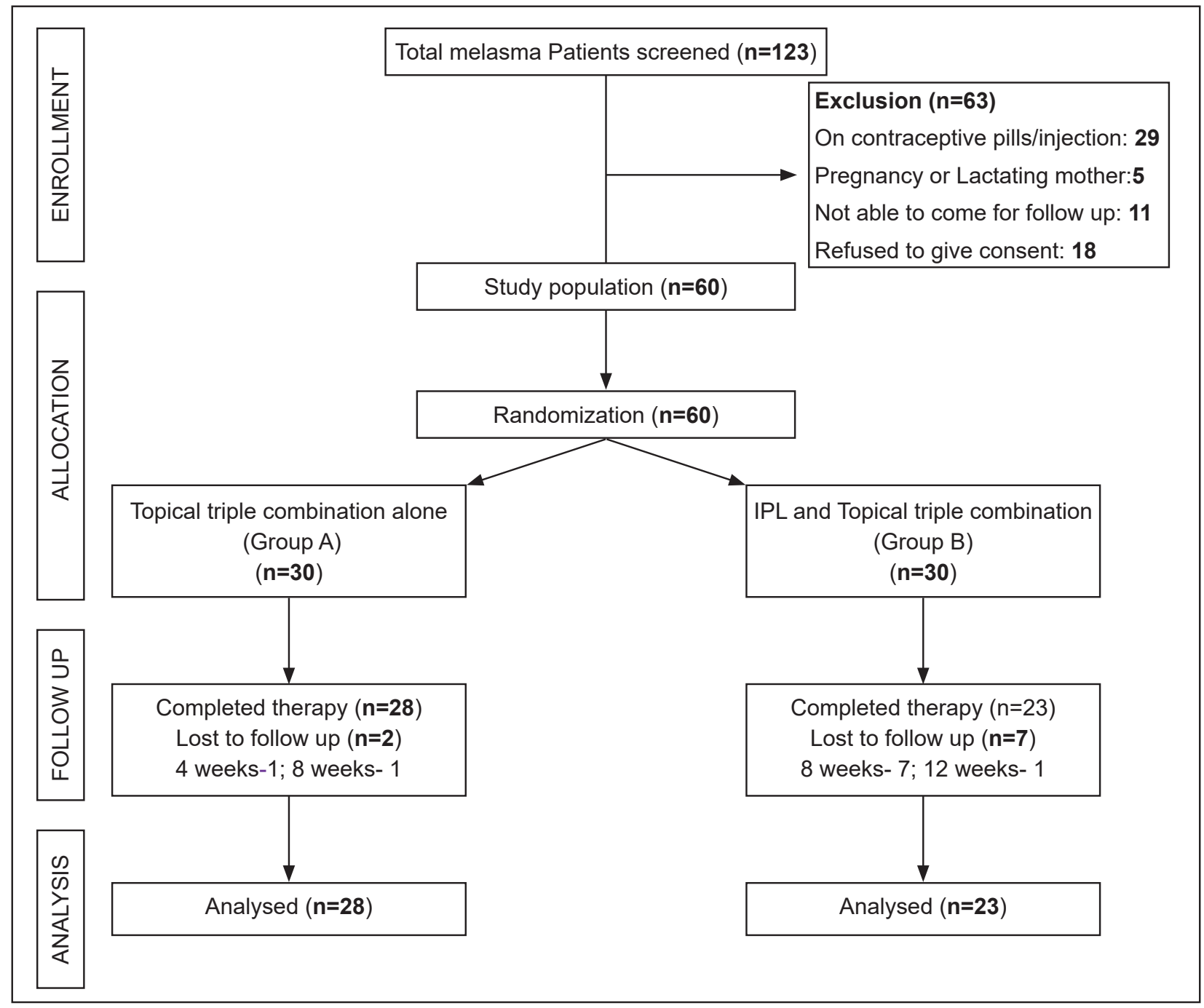

Figure 1: Flow diagram of the patient through different stages 


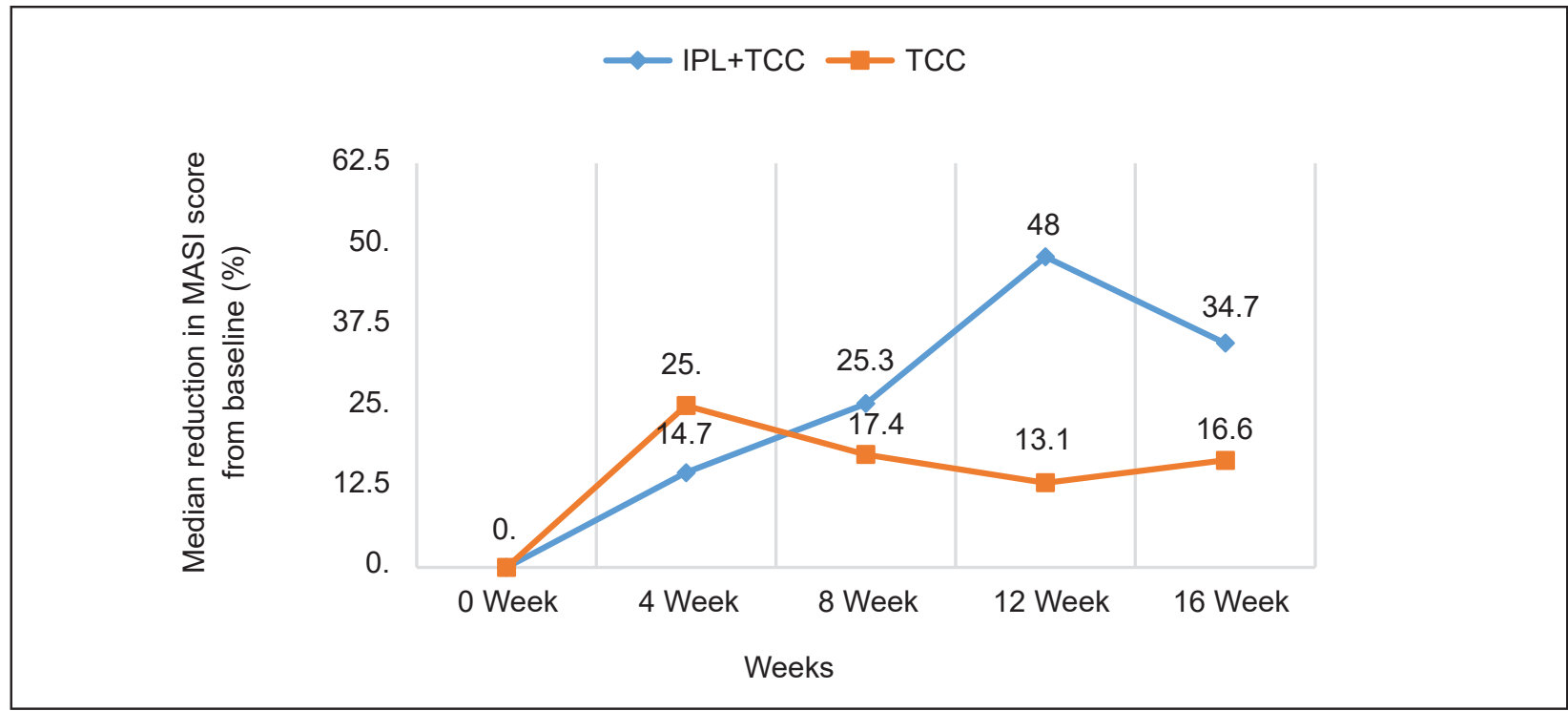

Figure 2: Comparison of percentage reduction in median MASI score between two groups
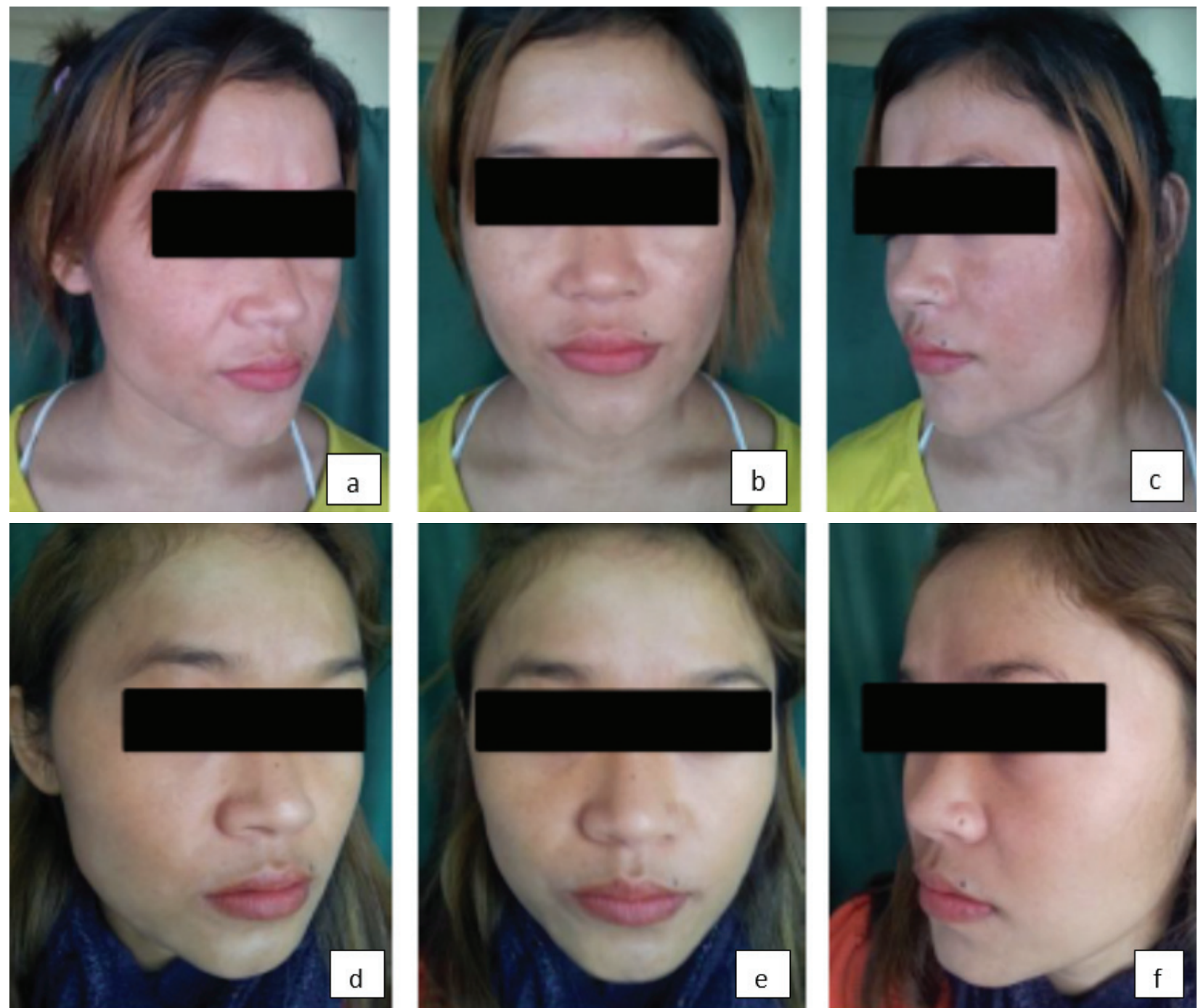

Figure 3: (a-f): Baseline MASI 28.4 before IPL + TCC treatment (a, b, c,), MASI reduction to 13 after 12 week (d ,e ,f); MASI reduction of $54.2 \%$ 

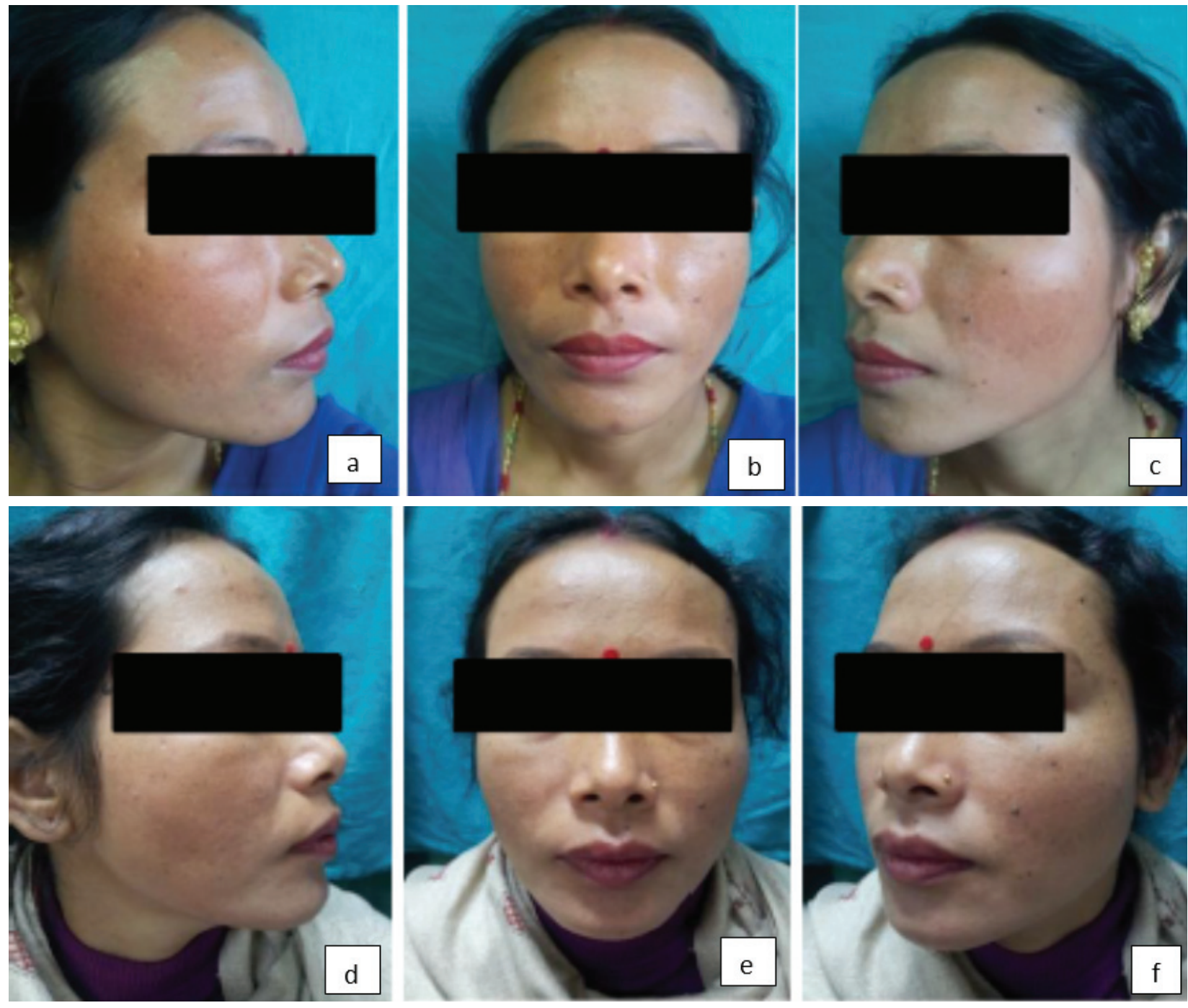

Figure 4: (a-f): Baseline MASI 26.4 before TCC treatment alone (a, b, c,), MASI reduction to 18.4 after 12 weeks (d, e, f); MASI reduction of $30.3 \%$

Table 1: Baseline characteristics of melasma patients in both the groups

\begin{tabular}{|c|c|c|c|c|c|c|}
\hline \multirow{2}{*}{\multicolumn{2}{|c|}{ Characteristics }} & \multicolumn{3}{|c|}{ Group } & \multirow{2}{*}{$\begin{array}{l}\text { Chi Square* / } \\
\text { t Test**/Mann } \\
\text { Whitney U } \\
\text { test*** }\end{array}$} & \multirow[b]{2}{*}{$P$ value } \\
\hline & & $\begin{array}{c}\text { TCC } \\
n=30\end{array}$ & $\begin{array}{c}I P L+T C C \\
n=30\end{array}$ & Total & & \\
\hline \multicolumn{2}{|c|}{ Age (years) Mean \pm SD (Median) } & $\begin{array}{c}32.33 \pm \\
6.55(33.5)\end{array}$ & $\begin{array}{l}29.77 \pm 4.81 \\
(30)\end{array}$ & $\begin{array}{c}31.05 \pm \\
5.85(30)\end{array}$ & $-1.728^{* *}$ & 0.089 \\
\hline \multirow{2}{*}{$\begin{array}{l}\text { Gender } \\
\mathrm{n}(\%)\end{array}$} & Female & $30(100)$ & $29(96.7)$ & $59(98.3)$ & \multirow{2}{*}{$1.017^{*}$} & \multirow{2}{*}{0.313} \\
\hline & Male & $0(0)$ & $1(3.3)$ & $1(1.7)$ & & \\
\hline \multirow{2}{*}{$\begin{array}{l}\text { Occupation } \\
\mathrm{n}(\%)\end{array}$} & Outdoor workers & $9(30)$ & $11(36.6)$ & $20(33.3)$ & \multirow{2}{*}{$2.833^{*}$} & \multirow[t]{2}{*}{0.418} \\
\hline & Others & $21(70)$ & $19(63.4)$ & 40 (66.7) & & \\
\hline \multicolumn{2}{|c|}{$\begin{array}{l}\text { Duration (years) Mean } \\
\pm \mathrm{SD} \text { (Median) }\end{array}$} & $\begin{array}{c}5.02 \pm 4.07 \\
(4.5)\end{array}$ & $4.4 \pm 3.70(4)$ & $\begin{array}{c}4.70 \pm 3.8 \\
(4)\end{array}$ & $-0.627 * *$ & 0.533 \\
\hline \multirow{4}{*}{$\begin{array}{l}\text { Precipitating } \\
\text { factors } \\
\text { n (\%) }\end{array}$} & Sun Exposure & $28(93.3)$ & $30(100)$ & 58 (96.7) & \multirow[b]{4}{*}{$2.069 *$} & \multirow{4}{*}{0.355} \\
\hline & Stress & $0(0)$ & $1(3.3)$ & $1(1.7)$ & & \\
\hline & Pregnancy & $11(36.7)$ & $5(16.7)$ & $16(26.7)$ & & \\
\hline & $\begin{array}{c}\text { Hormonal } \\
\text { contraceptives }\end{array}$ & $15(50)$ & $12(40)$ & $27(45)$ & & \\
\hline
\end{tabular}




\begin{tabular}{|c|c|c|c|c|c|c|}
\hline \multirow{2}{*}{\multicolumn{2}{|c|}{ Characteristics }} & \multicolumn{3}{|c|}{ Group } & \multirow{2}{*}{$\begin{array}{c}\text { Chi Square* / } \\
\text { t Test**/Mann } \\
\text { Whitney U } \\
\text { test*** }\end{array}$} & \multirow[b]{2}{*}{$P$ value } \\
\hline & & $\begin{array}{c}\text { TCC } \\
n=30\end{array}$ & $\begin{array}{c}\mathrm{IPL}+\mathrm{TCC} \\
\mathrm{n}=\mathbf{3 0}\end{array}$ & Total & & \\
\hline \multicolumn{2}{|c|}{$\begin{array}{l}\text { Sun exposure (hours / week) } \\
\text { Mean } \pm \text { SD (Median) }\end{array}$} & $\begin{array}{c}9.45 \pm \\
12.29(7)\end{array}$ & $\begin{array}{c}13.1 \pm \\
12.56(7)\end{array}$ & $\begin{array}{c}11.338 \pm 12.45 \\
\text { (7) }\end{array}$ & $1.208^{* *}$ & 0.232 \\
\hline \multicolumn{2}{|c|}{ Family history $\mathrm{n}(\%)$} & $13(43.3)$ & $15(50)$ & $28(46.7)$ & $0.268 *$ & 0.605 \\
\hline \multicolumn{2}{|c|}{$\begin{array}{l}\text { History of past treatment } \\
\mathrm{n}(\%)\end{array}$} & $21(70)$ & $19(63.4)$ & $40(66.7)$ & $3^{*}$ & 0.392 \\
\hline \multirow{2}{*}{$\begin{array}{l}\text { Skin photo types } \\
\text { n (\%) }\end{array}$} & II \& III & $8(26.6)$ & 14 (46.6) & $22(36.7)$ & \multirow{2}{*}{$3.924 *$} & \multirow[t]{2}{*}{0.270} \\
\hline & IV \& V & $22(73.4)$ & $16(53.4)$ & $38(63.3)$ & & \\
\hline \multirow{2}{*}{$\begin{array}{l}\text { Pattern } \\
\mathrm{n}(\%)\end{array}$} & Centro-facial & $29(96.7)$ & $30(100)$ & $59(98.3)$ & \multirow{2}{*}{$1.017 *$} & \multirow{2}{*}{0.313} \\
\hline & Malar & $1(3.3)$ & $0(0)$ & $1(1.7)$ & & \\
\hline
\end{tabular}

Table 2: Change in MASI score from baseline to follow - up in both the groups

\begin{tabular}{|c|c|c|c|}
\hline \multirow{2}{*}{ WEEK } & IPL + TCC $(\mathbf{n}=\mathbf{2 8})$ & TCC $(\mathbf{n}=\mathbf{2 3})$ & \multirow{2}{*}{ p- VALUE } \\
\cline { 2 - 3 } & MEAN \pm SD (MEDIAN) & MEAN \pm SD (MEDIAN) & 0.332 \\
\hline 0 (BASELINE) & $15.3077 \pm 4.0177(15)$ & $16.3929 \pm 5.760(17.2)$ & 0.884 \\
\hline 4 Week & $13.7 \pm 5.0815(12.8)$ & $13.4357 \pm 4.895(12.9)$ & 0.560 \\
\hline 8 Week & $11.9615 \pm 4.627(11.2)$ & $13.6357 \pm 6.886(14.2)$ & 0.009 \\
\hline 12 Week & $8.8615 \pm 3.895(7.8)$ & $14.6143 \pm 6.0214(14.95)$ & 0.072 \\
\hline
\end{tabular}

Table 3: Physician's global assessment of response in both treatment groups

\begin{tabular}{|c|c|c|c|c|c|}
\hline Weeks & Physician global assessment & $\begin{array}{c}\text { IPL + TCC } \\
n=28 \\
n(\%)\end{array}$ & $\begin{array}{c}\text { TCC } \\
n=23 \\
n(\%)\end{array}$ & Chi square & $p$-value \\
\hline \multirow{2}{*}{4 WEEKS } & Almost clear to moderate improvement & $7(25.0)$ & $7(30.4)$ & \multirow{2}{*}{0.0187} & \multirow{2}{*}{0.8665} \\
\hline & Slight improvement to worse & $21(75.0)$ & $16(69.6)$ & & \\
\hline \multirow{2}{*}{8 WEEKS } & Almost clear to moderate improvement & $13(46.4)$ & $6(26.1)$ & \multirow{2}{*}{2.235} & \multirow{2}{*}{0.134} \\
\hline & Slight improvement to worse & $15(53.6)$ & $17(73.9)$ & & \\
\hline \multirow[t]{2}{*}{12 WEEKS } & Almost clear to moderate improvement & $16(57.2)$ & $5(21.7)$ & \multirow{2}{*}{6.534} & \multirow{2}{*}{0.010} \\
\hline & Slight improvement to worse & $12(42.9)$ & $18(78.3)$ & & \\
\hline \multirow[t]{2}{*}{16 WEEKS } & Almost clear to moderate improvement & $12(42.8)$ & $5(21.7)$ & \multirow{2}{*}{2.534} & \multirow{2}{*}{0.111} \\
\hline & Slight improvement to worse & $16(57.2)$ & $18(78.3)$ & & \\
\hline
\end{tabular}

Table 4: Number of patients with relapse in both the groups as per protocol analysis

\begin{tabular}{|c|c|c|c|c|c|}
\hline Relapse & $\begin{array}{c}\text { IPL }+ \text { TCC } \\
(\mathbf{n}=\mathbf{2 8})\end{array}$ & $\begin{array}{c}\text { TCC } \\
(\mathbf{n}=\mathbf{2 3})\end{array}$ & $\begin{array}{c}\text { TOTAL } \\
(\mathbf{n}=\mathbf{5 1})\end{array}$ & CHI SQUARE & p - VALUE \\
\cline { 1 - 3 } Present & $2(7.14 \%)$ & $3(13.04 \%)$ & $5(9.80 \%)$ & 0.4972 & 0.480 \\
\hline Absent & $26(92.86 \%)$ & $20(86.96 \%)$ & $46(90.2 \%)$ & \\
\hline
\end{tabular}

Table 5: Number of patients with adverse effects in both the treatment groups

\begin{tabular}{|c|c|c|c|}
\hline ADVERSE EFFECTS & $\begin{array}{c}\text { IPL + TCC } \\
(n=28)\end{array}$ & $\begin{array}{c}\text { TCC } \\
(n=23)\end{array}$ & $\begin{array}{c}\text { TOTAL } \\
(n=51)\end{array}$ \\
\hline ERYTHEMA & $28(100 \%)$ & $23(100 \%)$ & $51(100 \%)$ \\
\hline TELANGIECTASIA & $4(14.2 \%)$ & 7 (30.4\%) & $11(21.5 \%)$ \\
\hline BURNING & $8(28.5 \%)$ & $0(0 \%)$ & $8(15.6 \%)$ \\
\hline URTICARIA & $1(3.5 \%)$ & $0(0 \%)$ & $1(1.96 \%)$ \\
\hline
\end{tabular}




\section{Discussion}

IPL is considered a promising treatment modality by delivering an evenly distributed pulsed light with lower fluency levels in various pigmentary conditions. It provides a safer and effective treatment of melasma in Asian populations. ${ }^{7,13}$ However, only a few randomized clinical trials studied the efficacy of intense pulse light alone or combined with bleaching agents. Moreover, there is variation in these studies with the number of IPL sessions ( 1 session to 4 sessions), time interval of between two sessions ( 2 weeks to 4 weeks), type of melasma (epidermal, mixed, dermal) and follow up (12 weeks- 12 months). Therefore, there is a need to study the optimal treatment parameters and number of sessions to determine the efficacy of the IPL.

In a previous study, single-session IPL followed by TCC was more effective than TCC therapy alone for mixed and dermal melasma treatment. ${ }^{9}$ The improvement in the pigmentation after one session of IPL combined with TCC was more (49.4\%) compared to another study that showed an improvement of $39.8 \%$ after 4 sessions of IPL with only hydroquinone cream (HQ). ${ }^{7}$ Despite 4 sessions of IPL done in the study done by Wang et al., ${ }^{7}$ the improvement was less, which could be due to the use of hydroquinone monotherapy alone. The beneficial effects of the combined components of TCC cream (fluocinolone acetonide $0.01 \%$, hydroquinone $4 \%$, and tretinoin $0.05 \%$ ) have been known for more than 30 years. Tretinoin changed the skin barrier, which facilitated the penetration of hydroquinone, whereas the corticosteroid component reduced the irritation associated with the retinoid and that the normalized retinoid skin thinning associated with the corticosteroid. In addition, the corticosteroid component suppressed the biosynthetic and secretory functions of melanocytes, suppressing melanin production. It has anti-inflammatory properties, which may reduce inflammation induced by IPL. ${ }^{14}$

Similarly, Goldman et al., $2011^{8}$ compared TCC cream on one side of the face and an inactive control cream on the other side of the face with two sessions of IPL and found melasma severity score was significantly decreased with TCC cream and IPL than with inactive cream and IPL $(p=0.02)$. In another randomized controlled trial, Shakeeb et al., $2018^{10}$ compared the efficacy of intense pulse light therapy (IPL) and triple combination cream (TCC) versus intense pulse light therapy alone and triple combination cream alone in epidermal melasma treatment in 32 patients in each group. TCC was applied daily at night for two months by TCC group patients while IPL therapy was given fortnightly alone or in combination with TCC for two months in the other two groups. The improvement was more (93.5\%) in the IPL+TCC group when compared with TCC alone (68.8\%) and IPL alone group $(62.5 \%) .{ }^{10}$ In our study, the combination of TCC along with two-session IPL was found to be more effective (48\%) than TCC therapy alone (13.0\%). However, the response was less in comparison to the study done by Shakeeb et al., ${ }^{10}$ because we decreased the frequency of TCC after 4 weeks to minimize the adverse effects of TCC, might be responsible for less improvement. Similarly, the increased number of IPL sessions alone or the addition of $\mathrm{HQ}$ alone may not be very effective in treating melasma.

Patients with epidermal melasma may respond more favorably to IPL therapy than those with mixed or dermal melasma, which could be related to melanin's location. ${ }^{13}$ In epidermal melasma, IPL promotes a rapid differentiation of keratinocytes followed by upward transfer of the melanosomes and shedding the melanosomes as micro crust from whereas in the mixed type melasma, dermal melanin-loaded macrophages are difficult to be damaged. Thus the therapeutic effects are attributed mainly to the photothermolysis of the melanosomes in the epidermis, ${ }^{13}$. However, we did not assess the response as per the type of melasma.

Partial repigmentation was observed in the longterm follow-up, indicating that a topical maintenance therapy and IPL session may be needed for at least 6 to 12 months post-treatment. Wang et al., 2004 observed relapse with IPL in $24.2 \%$ of the participants at 24-week post-treatment. However, we found low relapse in both groups of IPL+TCC (7.14\%) and TCC (13.04\%) patients in and TCC alone treatment group respectively at 16 weeks. The low relapse could be because of shorter follow-up duration at 16-week in our study compared to 24-week in the previous study. ${ }^{7}$

The most frequently reported events were erythema (100\%) followed by burning sensation (28.5\%) after the IPL treatment, which disappeared after a simple ice pack application. Only 1 (7.69\%) patient in IPL+TCC group had urticarial over the extensor aspect of the right arm. This might be a coincidental finding as there was no association with the procedure. In the TCC group, 23 (100\%) experienced a mild to moderate erythema over the face. Telangiectasia was noted more in the TCC group (30.4\%) than in the IPL+TCC (14.2\%) group. IPL has the advantages of targeting vascular structure and thus might minimize the adverse effect of TCC. Passeron et al., 2011 reported that half of the patients with dark skin developed a PIH whereas Wang et al., noted $\mathrm{PIH}$ in $11.7 \%$ patients. ${ }^{7,15}$. Therefore, a lower fluence should be used with caution in patients 
with dark skin phototypes. In our study, none of the patients had developed PIH. It could be because of low fluence IPL and continuous use of TCC in our study.

The major strength of this study is that it is a randomized trial on the efficacy of IPL + TCC for melasma treatment compared with TCC alone. The design ensured the wider inclusion of patients who were clinically eligible for IPL therapy. Our study provides appropriate evidence for the practitioners, allowing definitive statements about the efficacy and safety of IPL in the treatment of melasma.

\section{References}

1. Gupta AK, Gover MD, Nouri K, Taylor S. The treatment of melasma: a review of clinical trials. J Am Acad Dermatol. 2006; 55 (6): 1048-65. https:// doi.org/10.1016/j.jaad.2006.02.009

2. Grimes PE. Melasma: etiologic and therapeutic considerations. Arch Dermatol. 1995; 131(12):1453-7. https://doi.org/10.1001/ archderm.131.12.1453.

3. Draelos ZD. Skin lightening preparations and the hydroquinone controversy. Dermatol Ther. 2007; 20 (5):308-13. https://doi.org/10.1111/j.1529 8019.2007.00144.x.

4. Rendon $\mathrm{M}$, Berneburg $\mathrm{M}$, Arellano I, Picardo M. Treatment of melasma. J Am Acad Dermatol. 2006; 54(5):S272-81. https://doi.org/10.1016/j. jaad.2005.12.039.

5. Vachiramon V, Sirithanabadeekul P, Sahawatwong S. Low-fluence Q-switched Nd: YAG 1064-nm laser and intense pulsed light for the treatment of melasma. J Eur Acad DermatolVenereol. 2015; 29(7):1339-46. https://doi.org/10.1111/ jdv. 12854

6. Huang $\mathrm{YL}$, Liao $\mathrm{YL}$, Lee $\mathrm{SH}$, Hong $\mathrm{HS}$, Huang $\mathrm{YL}$, Intense pulsed light for the treatment of facial freckles in Asian skin. Dermatol Surg. 2002; 28 (11): 1007-12. https://doi.org/10.1046/J.15244725.2002.02103.x

7. Wang CC, Hui CY, Sue YM, Wong WR, Hong HS. Intense pulsed light for the treatment of refractory melasma in Asian persons. Dermatol Surg. 2004; 30 (9):1196-200. https://doi.org/10.1111/j.15244725.2004.30371.x

8. Goldman MP, Gold MH, Palm MD, Colón LE, Preston N, Johnson LA et al. Sequential treatment with triple combination cream and intense pulsed light is more efficacious than sequential treatment with an inactive (control) cream and intense pulsed light in patients with moderate to severe melasma. Dermatol Surg.

\section{Limitations and Conclusion}

Because of the short follow-up period and the longterm side effects of IPL and TCC, the relapse duration could not be evaluated in the present study. However, our study supports previous studies that IPL could be an effective and well-tolerated treatment option to treat melasma if combined with triple combination therapy. We recommend further studies, including a long-term follow-up to detect chronic side effects of $\mathrm{IPL}$ and relapse rate.

2011;37(2):224-33. https://doi.org/10.1111/ j.1524-4725.2010.01849.x

9. Figueiredo SL, Trancoso SS. Single-session intense pulsed light combined with stable fixeddose triple combination topical therapy for the treatment of refractory melasma. Dermatol Ther. 2012; 25(5):477-80. https://doi.org/10.1111/ j.1529-8019.2012.01530.x

10. Shakeeb N, Noor SM, Ullah G, Paracha MM. Efficacy of Intense Pulse Light Therapy and Tripple Combination Cream Versus Intense Pulse Light Therapy and Tripple Combination Cream Alone in Epidermal Melasma Treatment. J Coll Physicians Surg Pak. 2018;28(1):13-6. https://doi. org/10.1111/ijd.12195

11. Yi J, Hong T, Zeng $H$, Li $P$, Li $P$, Wang $S$, Chen J, Li $P$, Zhou J. A Meta-analysis-Based Assessment of Intense Pulsed Light for Treatment of Melasma. Aesthetic Plast Surg. 2020; 44(3):947-952. https:// doi.org/10.1007/s00266-020-01637-x

12. Kimbrough Green CK, Griffiths CE, Finkel LJ. Topical retinoic acid (tretinoin) for melasma in black patients. A vehicle controlled clinical trial. Arch Dermatol. 1994; 130 (6):727-33.

13. Li YH, Chen JZS, Wei HC, Wu Y, Liu M, Xu YY et al. Efficacy and safety of intense pulsed light in treatment of melasma in Chinese patients. Dermatol Surg. 2008; 34 (5):693-701. https://doi. org/10.1111/j.1524-4725.2008.34130.x

14. Zimmermann GR, Avery W, Finelli AL, Farwell M, Fraser CC, Borisy AA. Selective amplification of glucocorticoid anti-inflammatory activity through synergistic multi-target action of a combination drug. Arthritis Res Ther. 2009;11(1):R12. https:// doi.org/10.1186/ar2602

15. Passeron $T$, Fontas $E$, Kang HY, Bahadoran $P$, Lacour J, Ortonne J. Melasma Treatment With Pulsed-Dye Laser and Triple Combination Cream: A Prospective, Randomized, Single-Blind, SplitFace Study. Arch Dermatol. 2011;147(9):1106-8. https://doi.org/10.1001/archdermatol.2011.255 